\title{
Comparison of Effectiveness of Drug-Coated Balloon Angioplasty versus Plain Balloon Angioplasty in Chronic Lower Extremity Ischemia Patients
}

This article was published in the following Dove Press journal:

International Journal of General Medicine

\author{
Iraj Nazari (iD) \\ Seyyed Masoud Mousavi' \\ Ahmad Sadeghpour' \\ Seyyed Mansour Alamshah (D) ${ }^{\prime}$ \\ Maryam Dastoorpoor (D) ${ }^{2}$ \\ 'Department of General Surgery, School \\ of Medicine, Ahvaz Jundishapur \\ University of Medical Sciences, Ahvaz, \\ Iran; ${ }^{2}$ Department of Biostatistics and \\ Epidemiology, Menopause Andropause \\ Research Center, Ahvaz Jundishapur \\ University of Medical Sciences, Ahvaz, \\ Iran
}

Background: Occlusive lesions of superficial femoral artery (SFA) in endovascular candidate patients are treated with balloon angioplasty with or without stenting. Recently, introduction of drug-coated balloon (DCB) angioplasty as a superior treatment option to plain balloon $(\mathrm{PB})$ has been challenging.

Objective: The purpose of this study was to compare the effectiveness of DCB versus PB angioplasty in chronic lower extremity ischemia patients.

Patients and Methods: In this clinical trial, 2 groups were matched at baseline; among 68 patients with peripheral artery disease, 23 patients were treated by DCB and 45 by PB. They were followed up for 6 months. Our findings of ABI, Rutherford and WIFI class changes, mortality, limb amputation, re-intervention and primary patency (PP) were collected and analyzed in comparative fashion between 2 groups.

Results: Mean patients age was 68.5 years (77.9\% male). At 6 months, the increase in ABI in $\mathrm{DCB}$ was 0.37 and in $\mathrm{PB}$ was $0.32(\mathrm{P}>0.05)$. Mean decrease in Rutherford class in $\mathrm{DCB}$ and $\mathrm{PB}$ were 2.56, $2.28(\mathrm{P}>0.05)$. Mean decrease in WIFI class in DCB and PB were 1.48, 1.11 ( $\mathrm{P}>0.05)$. In DCB group, 1 (4.3\%) limb amputation, 3 (13\%) re-interventions and no mortality with $87 \%$ PP were seen. In PB group, 2 (4.4\%) limb amputation, 7 (15.6\%) reinterventions, $1(2.2 \%)$ mortality with $84.4 \%$ PP were seen.

Conclusion: Treatment of occlusive lesions of SFA with DCB probably may leads to improvement in ABI, Rutherford and WIFI class, higher pp and lower rate of re-interventions. Since Rutherford class and pp in DCB group have improved during 6 months compared to 1 month follow up (in our study), this improvement seems to be more significant statistically in longer term of follow up.

Keywords: angioplasty, drug-coated balloon; DCB, paclitaxel, peripheral vascular disease

\section{Background}

Peripheral vascular disease is a worldwide disease that affects more than 200 million people and this has increased in recent years due to better life expectancy. ${ }^{1}$ Peripheral artery disease is caused by atherosclerotic plaques, leading to narrowing and blockage of the main artery supplying the lower limbs. Lower extremity arterial occlusion causes morbidity and mortality in patients and shows a range of clinical manifestations. This spectrum includes asymptomatic vascular occlusion, intermittent claudication, and critical limb ischemia. ${ }^{2}$ Modifying of the risk factors for peripheral vascular disease
Correspondence: Ahmad Sadeghpour Department of General Surgery, School of Medicine, Ahvaz Jundishapur University of Medical Sciences, Ahvaz, Iran

Email dr.ahmadsadeghpour@gmail.com 
include smoking cessation, exercise, control of blood pressure, diabetes and dyslipidemia, drug therapy and surgical treatment for vascular revascularization is advised strongly. Endovascular treatment became more common for these patients with the introduction of minimally invasive vascular techniques. ${ }^{1,3}$

Endovascular treatment includes plain balloon angioplasty (PB), bare stent, drug-coated balloon (DCB) angioplasty and drug-eluting stent (DES) that the surgeon after physical examination and considering the anatomic features of the arterial lesion, the disease pattern, the patient's functional state, the presence of previous interventions, Ischemia, etc., decides the type of treatment. DCB includes the combination of balloon angioplasty and paclitaxel release as an anti-proliferative and anti-inflammatory agent inside the vessel wall during balloon inflation which, with cytotoxic and antimitotic properties, inhibits neointimal hyperplasia, and seems to prevent or delay future vascular occlusion probably. ${ }^{4}$

In some recent studies, resulting in reduced economic, social, and psychological burden from PB failure complications such as amputation, re-admission, disability, inactivity and prosthetic costs, the use of the DCB is probably cost-effective and reasonable.

\section{Objectives}

Since there is disagreement among the authors about the efficacy of DCB over PB, this study investigated the efficacy of DCB comparison with $\mathrm{PB}$ in patients with chronic lower extremity ischemia, to better management of existing resources and facilities will lead to improvements in the quality of treatment and quality of life for patients, as well as in improving the health and well-being of patients and the community.

\section{Patients and Methods Type of Study}

This study was a randomized controlled clinical trial. The study population consisted of patients with chronic critical limb ischemia due to superficial femoral artery (SFA) atherosclerotic lesions. Then patients were asked their history and underwent a physical examination, including ankle-brachial index (ABI) and CT Angiography.

\section{Sample Size and Sampling}

Patients were restricted to accessing the case, given that patients had to meet all conditions of the study and fully consent to participate in the study, as well as being followed for 6 months after surgery. Therefore, in order to increase the test capability, the number of PB patients was doubled. Finally, from among the eligible patients, 23 patients entered the DCB group and 45 patients entered the PB group.

\section{Inclusion Criteria}

Patients in Rutherford class 4 to 6, TASC: A, B, single, de novo, non-in-stent stenosis arterial lesion, blood creatinine less than $1.5 \mathrm{mg} / \mathrm{dL}$, no cerebrovascular attack (CVA) less than 3 months, no prior surgery on SFA, no severe calcified lesion and chronic symptoms.

All of the patients were managed and followed by the same group of surgeons. After informed consent and matching regarding age, sex, smoking, hypertension, dyslipidemia, diabetes, history of ischemia, Rutherford's class TASC status, WIFI stage, and GLASS. In order to reduce the bias that was created, patients were randomly divided into 2 groups: $\mathrm{DCB}$ and $\mathrm{PB}$, in a preoperative visit. In the operating room, under local anesthesia, the same or opposite femoral artery was accessed, under fluoroscopic guide, then angiography was performed and the lesion's anatomy and its characteristics, including length and diameter, collateral artery inflow, and run off, were evaluated and TASC and GLASS category was revealed. Then the balloon is passed through the lesion and inflated for 3 minutes according to arterial characteristics to eliminate narrowing of the artery. Complementary angiography was then performed and arterial patency was observed. In case of remaining arterial stenosis, more than $20 \%$ of patients underwent stenting. Patients were followed up before discharge, 1 month and 6 months at the clinic after surgery, and symptoms, change of ABI, Rutherford class, need for reoperation, and need for lower extremity amputation, mortality and primary patency (PP) were monitored. Information related to each patient was entered in the check list.

The DCB and PB used in this study was BARD (made in the US) and IVASCULAR (made in Spain), due to the characteristics of arteries and arterial lesions, the proper size was used. The amount of paclitaxel in DCB was $2 \mathrm{ng} / \mathrm{mm}^{2}$.

\section{Data Analysis}

The statistics descriptive, such as the distribution of frequency, mean and standard deviation were used. ShapiroWilk test was used to evaluate normality. Independentsamples $t$-test and Mann-Whitney $U$-test were used to compare the mean of the main variables according to the 
intervention and control groups. Paired $t$-test and Wilcoxon signed-rank test were used to compare the mean of the main variables before and after the intervention. Finally, a Chi-square test was used to compare the frequency distribution of qualitative variables according to the studied groups. The significance level of less than 0.05 was considered. To analyze dataSPSS Version 22 was used.

\section{Ethical Considerations}

Informed written and verbal consent was obtained from patients who volunteered to participate in the study and were assured that their information was confidential and would not be harmed if they withdrew from the study. The Ethics License of the present study was acquired from the Ethics Committee of Ahvaz Jundishapur University of Medical Sciences (Code of ethics: IR.AJUMS. REC.1397.849). This trial was conducted in accordance with the Declaration of Helsinki. The study protocol was registered at Iranian Registry of Clinical Trials with No: IRCT20180520039745N1.

\section{Results}

The mean age in DCB group was $69.5 \pm 6.5$ years with a minimum and maximum of 56 and 80 years. Also in PB group mean age was $68 \pm 6.2$ with a minimum and a maximum of 58 and 82 years old. In the DCB group and the PB group, $78.3 \%$ and $77.8 \%$ were male, respectively. In terms of smoking status, $69.6 \%$ of the DCB group and $66.7 \%$ of the PB group were current smokers. In the DCB group and the PB group, $82.6 \%$ and $84.4 \%$ were blood hypertensive, respectively. In terms of type 2 diabetes, $43.5 \%$ in the DCB group and $46.7 \%$ in the PB group had type 2 Diabetes. In the DCB group and the PB group, $65.2 \%$ and $71.1 \%$ had Dyslipidemia, respectively. In the DCB group and the PB group, 52.2\% and 46.7\% had ischemic heart disease (IHD), respectively. Regarding TASC classification, in the DCB group and the PB group, $69.6 \%$ and $62.2 \%$ were in class $A$, respectively, and the rest were in class B. In the DCB group and the $\mathrm{PB}$ group, $21.7 \%$ and $20 \%$ had a history of attack (CVA, respectively. In terms of the type of vascular disease during CT angiography, $69.6 \%$ of the DCB group and $62.2 \%$ of the PB group were in the TASC A group. The resultsin Table 1 show that no significant difference in the DCB and PB groups in terms of the demographic and clinical variables was observed. So these variables were homogeneous in the base line (P-value> 0.05).
Table I Mean and Frequency Distribution of Demographic and Clinical Variables in DCB and PB Groups in Base Line

\begin{tabular}{|l|l|l|l|}
\hline Variables & $\begin{array}{l}\text { Drug-Coated } \\
\text { Balloon } \mathbf{( n = 2 3 )}\end{array}$ & $\begin{array}{l}\text { Plain } \\
\text { Balloon } \\
(\mathbf{n}=45)\end{array}$ & p-value \\
\hline Age & $69.5 \pm 6.5$ & $68.0 \pm 6.2$ & 0.367 \\
Male & $78.3(18)$ & $77.8(35)$ & 0.964 \\
Smoker & $69.6(16)$ & $66.7(30)$ & 0.809 \\
Type2 diabetes mellitus & $43.5(10)$ & $46.7(21)$ & 0.803 \\
Dyslipidemia & $65.2(15)$ & $71.1(32)$ & 0.619 \\
IHD & $52.2(12)$ & $46.7(21)$ & 0.667 \\
CVA & $21.7(5)$ & $20(9)$ & 0.867 \\
Blood pressure(HTN) & $82.6(19)$ & $84.4(38)$ & 0.846 \\
Average Rutherford grade & $4.6 \pm 0.7$ & $4.5 \pm 0.6$ & 0.757 \\
ABI & $0.43 \pm 0.11$ & $0.47 \pm 0.10$ & 0.107 \\
WIFI stage & $2.48 \pm 0.9$ & $2.40 \pm 0.7$ & 0.927 \\
\hline TASC & & & 0.549 \\
A & $69.6(16)$ & $62.2(28)$ & \\
B & $30.4(7)$ & $27.8(17)$ & \\
\hline GLASS & & & 0.549 \\
Class I & $69.6(16)$ & $62.2(28)$ & \\
Class 2 & $30.4(7)$ & $27.8(17)$ & \\
\hline
\end{tabular}

The results showed that the mean ABI score In DCB group was $0.43 \pm 0.11$ before the intervention and $0.80 \pm 0.116$ months after the intervention, with a 0.37 increase $(\mathrm{p}<0.001)$. The mean ABI score in the PB group before and after intervention was $0.47 \pm 0.10$ and $0.79 \pm 0.12$, respectively, with an increase of $0.32(\mathrm{p}<0.001)$ (Table 2).

Mean WIFI stage in DCB group was $2.48 \pm 0.90$ before

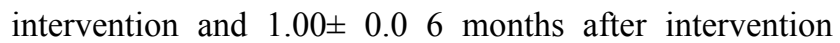
with a 1.48 decrease $(\mathrm{p}<0.001)$. In the PB group the mean WIFI stage before and 6 months after the intervention was $2.40 \pm 0.72$ and $1.29 \pm 0.70$ respectively, which showed a 1.11 decrease $(\mathrm{p}<0.001)$ (Table 3$)$.

Mean the Rutherford class score in the DCB group before the intervention was $4.56 \pm 0.73$, 1month after it was $1.95 \pm 0.97$ and 6 months after it was $2.0 \pm 0.65$. The Rutherford class score in the PB group was $4.51 \pm 0.87$, $1.89 \pm 0.63$ and $2.23 \pm 1.17$ respectively.

A decrease in the mean Rutherford class score in 1 month and 6 months relative to baseline in DCB group was 2.61 and 2.56, respectively, and in the PB group were 2.62 and 2.28 respectively $(p<0.001)$ (Table 4$)$. Based on the findings of Chart 3, the Rutherford index showed a greater improvement and decrease in DCB group than PB group after 6 months of follow-up. However, this difference was not statistically significant $(\mathrm{p}>0.05)$. 
Table 2 Comparison of Mean ABI Score Before and After the Intervention in DCB and PB Group

\begin{tabular}{|l|l|l|l|l|l|}
\hline & Time & Mean & Standard Deviation & Wilcoxon Statistic & P-value \\
\hline DCB group & & & & -4.320 & $<0.001$ \\
& Before intervention & 0.43 & 0.11 & & \\
& After 6 months & 0.80 & 0.11 & -5.957 & $<0.001$ \\
\hline PB group & & & 0.10 & & \\
& Before intervention & 0.47 & 0.12 & & \\
& After 6 months & 0.79 & & & \\
\hline
\end{tabular}

Table 3 Comparison of Mean WIFI Score Before and After the Intervention in DCB and PB Group

\begin{tabular}{|l|l|l|l|l|l|}
\hline & Time & Mean & Standard Deviation & Wilcoxon Statistic & P-value \\
\hline DCB group & & & & -3.948 & $<0.001$ \\
& Before intervention & 2.48 & 0.9 & & \\
& After 6 months & 1.00 & 0.0 & -5.391 & $<0.001$ \\
\hline PB group & & & & & \\
& Before intervention & 2.40 & 0.72 & & \\
& After 6 months & 1.29 & 0.70 & \\
\hline
\end{tabular}

Table 4 Comparison of Rutherford Class Inter and Intra Group of DCB and PB Group

\begin{tabular}{|c|c|c|c|c|c|c|c|c|}
\hline & Time & Group & Mean & $\begin{array}{l}\text { Standard } \\
\text { Deviation }\end{array}$ & $\begin{array}{l}\text { Compare } \\
\text { Means }\end{array}$ & P-value* & $\begin{array}{l}\text { Compare } \\
\text { Means }\end{array}$ & p-value*** \\
\hline & $\begin{array}{l}\text { Before } \\
\text { intervention }\end{array}$ & $\begin{array}{l}\text { DCB } \\
\text { PB }\end{array}$ & $\begin{array}{l}4.56 \\
4.51\end{array}$ & $\begin{array}{l}0.73 \\
0.63\end{array}$ & 0.05 & 0.757 & $\begin{array}{l}- \\
-\end{array}$ & $\begin{array}{l}- \\
-\end{array}$ \\
\hline \multirow[t]{3}{*}{$\begin{array}{l}\text { Rutherford } \\
\text { class }\end{array}$} & $\begin{array}{l}\text { After } \\
\text { intervention }\end{array}$ & $\begin{array}{l}\text { DCB } \\
\text { PB }\end{array}$ & $\begin{array}{l}2.22 \\
1.93\end{array}$ & $\begin{array}{l}1.31 \\
0.99\end{array}$ & 0.28 & 0.351 & $\begin{array}{l}2.34 \\
2.58\end{array}$ & $\begin{array}{l}<0.001 \\
<0.001\end{array}$ \\
\hline & After I month & $\begin{array}{l}\text { DCB } \\
\text { PB }\end{array}$ & $\begin{array}{l}1.95 \\
1.89\end{array}$ & $\begin{array}{l}0.97 \\
0.87\end{array}$ & 0.07 & 0.520 & $\begin{array}{l}2.61 \\
2.62\end{array}$ & $\begin{array}{l}<0.001 \\
<0.001\end{array}$ \\
\hline & After 6 months & $\begin{array}{l}\mathrm{DCB} \\
\mathrm{PB}\end{array}$ & $\begin{array}{l}2.00 \\
2.23\end{array}$ & $\begin{array}{l}0.65 \\
1.17\end{array}$ & -0.23 & 0.729 & $\begin{array}{l}2.56 \\
2.28\end{array}$ & $\begin{array}{l}<0.001 \\
<0.001\end{array}$ \\
\hline
\end{tabular}

Onemonth and 6 months PP, respectively, in DCB were $91.3 \%$ and $87 \%$ and in $\mathrm{PB}$ group were $97.7 \%$ and $84.4 \%$, respectively. In DCB group, there was 1 case $(4.3 \%)$ of limb amputation, $3(13.0 \%)$ re-intervention and survival rate was $100 \%$. In PB group there were 2 cases $(4.4 \%)$ of amputation, 7 cases $(15.6 \%)$ reintervention and one case $(2.2 \%)$ of mortality (Table 5). Two cases in the DCB and 1 case in the PB group needed stenting because of residual stenosis. We did not encounter any distal embolization or any other problems regarding to safety of $\mathrm{DCB}$ and $\mathrm{PB}$.

\section{Discussion}

The results of this study showed that of the 68 patients, the mean age was 68.5 years. Most of the patients were men, and less than half were diabetics and most were smokers. Hypertension was present in $83.8 \%$ and about $69.1 \%$ had dyslipidemia. In all, a total of $48.5 \%$ had a history of IHD 
Table 5 Mean Difference and Frequency Distribution of Main Outcomes of Study by DCB and PB Group I and 6 Months After Intervention

\begin{tabular}{|c|c|c|c|c|c|}
\hline Variables & $\begin{array}{l}\text { Drug- } \\
\text { Coated } \\
\text { Balloon } \\
(n=23) \\
\text { I Month }\end{array}$ & $\begin{array}{l}\text { Plain Balloon } \\
(n=45) \\
\text { I Month }\end{array}$ & $\begin{array}{l}\text { Drug-Coated Balloon } \\
(n=23) \\
6 \text { Months }\end{array}$ & $\begin{array}{l}\text { Plain Balloon } \\
(n=45) \\
6 \text { Months }\end{array}$ & p-value \\
\hline Mean $A B I$ improvement from base line & - & - & 0.37 & 0.32 & 0.758 \\
\hline $\begin{array}{l}\text { Mean WIFI staging improvement from base } \\
\text { line }\end{array}$ & - & - & 1.48 & 1.11 & 0.058 \\
\hline $\begin{array}{l}\text { Mean Rutherford class improvement from } \\
\text { base line }\end{array}$ & 2.61 & 2.62 & 2.56 & 2.28 & 0.729 \\
\hline Primary patency & $21(91.3 \%)$ & $44(97.7 \%)$ & $20(87.0 \%)$ & $38(84.4 \%)$ & 0.782 \\
\hline Limb amputation & - & - & $\mathrm{I}(4.3 \%)$ & $2(4.4 \%)$ & 0.985 \\
\hline Re-intervention & - & - & $3(13.0 \%)$ & $7(15.6 \%)$ & 0.782 \\
\hline Mortality & - & - & $0(0.0 \%)$ & $\mathrm{I}(2.2 \%)$ & 0.662 \\
\hline
\end{tabular}

and $20.5 \%$ had a history of CVA. In Group A $64.8 \%$ of patients were classified with TASC, and $35.2 \%$ in the group B.Mean Preoperative ABI and 6 months follow up were 0.43 and 0.8 in DCB group,and 0.47 and 0.79 in PB group respectively, which showed a significant increase compared to the preoperative. This means that the use of DCB and PB may increase ABI Patients in the period of 6 months is the increase by 0.37 and 0.32 in the DCB and PB group respectively.In the study of Brodmann et al, ABI change after drug balloon angioplasty at 6 and 12 months follow-up was reported 0.23 and 0.17 , respectively. ${ }^{1}$ In the Scheinert et al, study 6 month and 2 year improvement ABI There were 0.2 and 0.2 in the DCB and 0.22 and 0.18 in the PB group, respectively. ${ }^{4}$ In the study by Werk et al with an 18-month follow-up, it was found that despite improvement of Rutherford's class, no changes were observed in ABI patients in each DCB and PB group before and after angioplasty. ${ }^{5}$ Consistent with our results, in the Laird et al study With 24-month follow-up, ABI changes there was an increase of 0.16 and 0.19 in the DCB and PB group, respectively, which was significant compared to the pre-intervention, but the difference between the 2 groups was not statistically significant. ${ }^{6}$ In the Rosenfield et al study with a 12 month follow up of ABI changes in the DCB and PB group, the increase was 0.17 and 0.18 , respectively, which was not significant. ${ }^{7}$

The results of this study showed that the mean preoperative and post- 1 and 6- month follow-up of Rutherford's class score were 4.56, 1.95 and 2 in DCB group and 4.51, 1.89 and 2.32 in the PB group, respectively, which were significantly higher than before practice shows. This means that the use of DCB and PB causes decrease Rutherford class in 6-month period, 2.56 and 2.28, respectively. It was also found that the Rutherford index improved more in the DCB group than the PB group after 6 months compared to the first month of follow-up.

In the study by Brodmann et al, the Rutherford class changes after DCB at 6 and 12 months follow-up was reported to be 2.39 and 2.45 , respectively. ${ }^{1}$ In the study by Scheinert et al the 6- month and 2-year changes of the Rutherford class were reported in the DCB group to be 1.7 and 2.1, and in the PB group to be 1.6 and 1.8, respectively. ${ }^{4}$ In the study by Rosenfield with a 12 month follow-up, the Rutherford class changed to 1.9 and 1.7, in the DCB and PB group, respectively. ${ }^{7}$

In this study the mean WIFI score in the preoperative and 6 month follow-up, was 2.48 and 1 in DCB and 2.40 and 1.29 in $\mathrm{PB}$, respectively, which shows significant improvement compared to pre-operation. That is the use of DCB and PB causes decrease in Patient's WIFI stage in the period of 6 months and the rate of decrease, respectively, 1.48 and 1.11 in DCB and PB. WIFI staging according to new references, is more practical and comprehensive than ABI and Rutherford. Since in the literature reviews, no studies have used this new and comprehensive criterion, this is one of the strengths of this study.

The results of this study show that the one month pp in the DCB and PB groups were $91.3 \%$ and $97.7 \%$, respectively, and the 6-month PP was $86.9 \%$ and $84.4 \%$, respectively, implying that 6 months' PP versus one month's PP in DCB compared to PB shows more improvement. 
The study by Schroeder et al 12 months PP after the DCB reported $89 \% .{ }^{8}$ In the study by Rosenfield et al oneyear PP was $65 \%$ for the DCB group and $52 \%$ for the PB group. ${ }^{7}$

In a multicenter study 6 months PP in DCB and PB $72 \%$ and $49 \%$, and the 24 months PP were $57 \%$ and $40 \%$, respectively. ${ }^{4}$ All 3 studies referred to such findings, although the PP rate after the DCB was more than PB, this difference was not statistically significant. But in the study by Schroeder et al, 12 month PP in the DCB (89\%) and in $\mathrm{PB}(65 \%)$ was a significant difference. ${ }^{9}$ In a metaanalysis, one year PP in DCB group was $74 \%$ and in $\mathrm{PB}$ was $64 \%$ with significant differences reported and proposed the use of DCB as an economic and cost-effective strategy. ${ }^{10}$ Also In another recent study, 12 months PP in DCB $(86 \%)$ and in PB (56\%) with a significant difference was reported. ${ }^{10}$ In the study by Werk et al, 6 months PP was reported in both DCB and PB $(94 \%) .{ }^{5}$ Considering different studies it seems, PP after DCB and PB is still challenging and long-term follow-up studies are strongly recommended.

In this study, the follow-up period of 6 months reintervention in $\mathrm{DCB}$ and $\mathrm{PB}, 13 \%$ and $15.6 \%$, respectively, the rate of limb amputation $4.3 \%$ and $4.4 \%$, respectively. There was one mortality (2.2\%) in the PB group. In the study by Scheinert et al, after 6 months follow-up in $\mathrm{DCB} 2 \%$ mortality, $2 \%$ amputation, and $13 \%$ reintervention were reported and in the PB group 6\% mortality and $24 \%$ re-intervention were reported. In the 24 month follow-up in the DCB group, $9 \%$ deaths, 36\% reintervention were reported, and in the PB group 11\% mortality and $51 \%$ re-intervention were reported. ${ }^{4}$ In the study by Werk et al, in the 6 month follow up in both groups $2 \%$ mortality with no amputation was reported. ${ }^{5}$ It seems that despite the lower mortality rate, reoperation and limb amputation in the DCB group in our study and also in literature, this difference was not statistically significant in all cases.

\section{Conclusion}

Since the treatment of femoropopliteal stenotic lesions in patients undergoing endovascular surgery is currently performed by angioplasty and stenting, and their complications are intimal neoplasia due to intervention-induced injury, DCB with the purpose of counteracting intimal neoplasia and the use of anti-mitotic, anti-proliferative and anti-inflammatory agents, such as paclitaxel, have emerged as an attractive option in the treatment of these vascular lesions, and theoretically, DCB are expected to provide equivalent to stents without leaving foreign bodies prone to fracture. Since the Rutherford and PP in this study showed a greater improvement in the DCB group than the PB group after six months compared to the first month of follow-up, it seems that this improvement and difference in the long term is more significant. And in longer follow-ups this difference may be statistically significant. Therefore, in order to investigate more precisely and determine the probability of DCB priority in patients with long-term follow-up, we recommend the use of more samples as well as a meta-analysis study to achieve a more comprehensive result.

\section{Data Sharing Statement}

De-identified patient data can be inquired from the corresponding author upon reasonable request.

\section{Acknowledgments}

This article is taken from the thesis in the subspecialty vascular and endovascular. We sincerely thank all the patients who participated in this study despite the many problems caused by the disease.

\section{Funding}

This study was funded and supported by Ahvaz Jundishapur University of Medical Sciences, Grant No: CVRC-9716.

\section{Disclosure}

The authors report no conflicts of interest for this work.

\section{References}

1. Brodmann M, Zeller T, Christensen J, et al. Real-world experience with a Paclitaxel-Coated Balloon for the treatment of atherosclerotic infrainguinal arteries: 12-month interim results of the BIOLUX P-III registry first year of enrolment. J Vasc Bras. 2017;16(4):276-284. doi:10.1590/1677-5449.007317

2. Cronenwett JL, Johnston KW. Rutherford's Vascular Surgery E-Book. Elsevier Health Sciences; 2014.

3. Katsanos K, Spiliopoulos S, Kitrou P, Krokidis M, Karnabatidis D. Risk of death following application of paclitaxel-coated balloons and stents in the femoropopliteal artery of the leg: a systematic review and meta-analysis of randomized controlled trials. J Am Heart Assoc. 2018;7(24):e011245. doi:10.1161/JAHA.118.011245

4. Scheinert D, Duda S, Zeller T, et al. The LEVANT I (Lutonix paclitaxel-coated balloon for the prevention of femoropopliteal restenosis) trial for femoropopliteal revascularization: first-in-human randomized trial of low-dose drug-coated balloon versus uncoated balloon angioplasty. JACC Cardiovasc Interv. 2014;7(1):10-19. doi:10.1016/j. jcin.2013.05.022

5. Werk M, Langner S, Reinkensmeier B, et al. Inhibition of restenosis in the femoropopliteal arteries. Aha J. 2008;13(118):1358-1365. 
6. Laird JR, Schneider PA, Tepe G, et al. Durability of treatment effect using a drug-coated balloon for femoropopliteal lesions: 24-month results of IN. PACT SFA. J Am Coll Cardiol. 2015;66 (21):2329-2338. doi:10.1016/j.jacc.2015.09.063

7. Rosenfield K, Jaff MR, White CJ, et al. Trial of a paclitaxel-coated balloon for femoropopliteal artery disease. $N$ Engl J Med. 2015;373 (2):145-153. doi:10.1056/NEJMoa1406235

8. Schroeder H, Meyer DR, Lux B, Ruecker F, Martorana M, Duda S. Two-year results of a low-dose drug-coated balloon for revascularization of the femoropopliteal artery: outcomes from the ILLUMENATE first-in-human study. Catheter Cardiovasc Interv. 2015;86(2):278-286. doi:10.1002/ccd.25900
9. Schroeder H, Werner M, Meyer D-R, et al. Low-dose paclitaxelcoated versus uncoated percutaneous transluminal balloon angioplasty for femoropopliteal peripheral artery disease: one-year results of the ILLUMENATE European randomized clinical trial (Randomized trial of a novel paclitaxel-coated percutaneous angioplasty balloon). Circulation. 2017;135(23):2227-2236. doi:10.1161/ CIRCULATIONAHA.116.026493

10. Sridharan ND, Boitet A, Smith K, et al. Cost-effectiveness analysis of drug-coated therapies in the superficial femoral artery. J Vasc Surg. 2018;67(1):343-352. doi:10.1016/j.jvs.2017.06.112

\section{Publish your work in this journal}

The International Journal of General Medicine is an international, peer-reviewed open-access journal that focuses on general and internal medicine, pathogenesis, epidemiology, diagnosis, monitoring and treatment protocols. The journal is characterized by the rapid reporting of reviews, original research and clinical studies across all disease areas. The manuscript management system is completely online and includes a very quick and fair peer-review system, which is all easy to use. Visit http://www.dovepress.com/ testimonials.php to read real quotes from published authors.

Submit your manuscript here: https://www.dovepress.com/international-journal-of-general-medicine-journal 